\title{
schestanem

\section{Observing patterns in MRI with QSM in Patients with SOD1 and C9ORF72 Genetic ALS}

Robin Warner, D0 ( $\sim$ robin.petrizzo@gmail.com )

Hospital for Special Surgery https://orcid.org/0000-0002-0590-5090

\section{Research Article}

Keywords: Amyotrophic Lateral Sclerosis, MRI, SOD1, C9ORF72

Posted Date: September 30th, 2020

DOl: https://doi.org/10.21203/rs.3.rs-83304/v1

License: (9) This work is licensed under a Creative Commons Attribution 4.0 International License. Read Full License

\section{EDITORIAL NOTE:}

January 20,2023: The full text of this preprint has been withdrawn by the authors as it was submitted and made public without the full consent of all the authors. Therefore, the authors do not wish this work to be cited as a reference. Questions should be directed to the corresponding author. 


\section{Abstract}

Introduction: The most common forms of familial ALS are due to the C9ORF72 and SOD1 genes. Pathology studies have demonstrated patients with C9ORF72 ALS tend to develop more protein aggregates in the cerebellum and temporal lobes, while SOD1 patients develop more protein aggregates in the frontal and temporal lobes. (REF). Other means of looking for these signs are not established. Currently, we use brain MRI quantitative susceptibility mapping analysis (QSM) to examine susceptibility in the motor cortex, which is typically increased in motor neuron disease, correlating with the clinical syndrome. We designed a study to retrospectively assess the MRI/QSM in genetic ALS patients for specific regional changes.

Methods: We retrospectively reviewed all genetic ALS patients seen in Neurology at Hospital for Special Surgery from 2013 through 2018 who had MRI with QSM. Our neuroradiologist carefully examined the scans of each patient.

Results: We found no distinguishing abnormalities in the brain MRIs of the genetic ALS patients reviewed. QSM of the motor cortices and corticospinal tracts showed increase in susceptibility, which is not unique to any specific type of ALS.

Discussion: MRI/QSM may not be useful in distinguishing ALS patients with the C9ORF72 or SOD1 mutations. This could reflect that the amount of protein aggregation may not be directly related to axonal loss, or that they affect certain neurons/tracts more than others.

\section{Introduction}

The most common form of familial ALS is due to the C9ORF72 gene. ${ }^{1}$ Patients with this kind of familial ALS tend to develop more protein aggregates in the cerebellum and temporal lobes on pathology. ${ }^{1-3}$ The second most common form of familial ALS is due to the SOD1 gene. ${ }^{1}$ Patients with this kind of genetic ALS tend to develop more protein aggregates in the frontal and temporal lobes, in addition to the anterior horns of the spinal cord on pathology. ${ }^{4-7}$ Other means of looking for these signs are not established. Brain MRI quantitative susceptibility mapping analysis (QSM) identifies degenerating neurons in the motor cortex because of abnormal iron deposition. ${ }^{3}$ Currently, we use this technique to examine susceptibility in the motor cortex, which is typically increased in motor neuron disease, correlating with the clinical syndrome and becomes more prominent as the burden of disease increases. ${ }^{3}$

We designed a study to retrospectively assess the MRI/QSM in Familial ALS patients with C9ORF72 and SOD1 genetic mutations for changes in the cerebellum and temporal lobes in C9ORF72 patients or the frontal, temporal and occipital lobes in SOD1 patients. Our goal was to use MRI/QSM to distinguish ALS patients with the C9ORF72 or SOD1 mutations from other kinds of genetic or sporadic ALS patients.

\section{Methods}


All patients with suspected ALS seen in Neurology at Hospital For Special Surgery from 2013 through 2018 having C9ORF72 or SOD1 mutations were reviewed retrospectively. In the C9ORF72 group, we identified 16 patients, 7 of which had an MRI with QSM. In the SOD1 group, we identified 8 patients, 3 of which had an MRI with QSM. Our neuroradiologist examined the scans of each patient with special attention to the cerebella and temporal lobes in the C9ORF72 group and the frontal and temporal lobes in the SOD1 group.

\section{Results}

Results are summarized in Table 1. We found no abnormalities in the cerebella or temporal lobes of any of the patients with C9ORF72 familial ALS who had MRI/QSM done. Likewise, we found no abnormalities in the frontal or temporal lobes of patients with SOD1 ALS who had MRI/QSM done. QSM of the motor cortices showed increase in susceptibility that correlated with disease burden, as measured by total MRC scores. This finding is not unique to any specific type of ALS. Only slightly increased susceptibility on QSM was seen in the patients with A4V subtype.

\section{Discussion}

The lack of distinguishing imaging findings to reflect pathological findings could reflect that the amount of iron deposition may not be directly related to protein aggregation or axonal loss, or that certain neurons or tracts are more affected than others. Susceptibility on QSM seen in patients with A4V subtype has been established to be less than in other types of ALS and our results support this. ${ }^{8}$ Since we found no distinguishing imaging features in the MRIs of patients with genetic ALS, we believe that MRI/QSM may not be useful in identifying ALS patients with C9ORF72 or SOD1 mutations. This study was limited by sample size, given the rarity of the disease and further rarity of its genetic subtypes. Future research to confirm the pathological differences between brain regions and to clarify the role of iron deposition in motor neuron disease would be helpful.

\section{Appendix 1: Tables}

Table 1: Summary of Results 


\begin{tabular}{|c|c|c|}
\hline $\begin{array}{l}\text { Subject \# } \\
\text { (mutation) }\end{array}$ & $\begin{array}{l}\text { Sum of } \\
\text { MRC } \\
\text { Strength } \\
\text { Scores }\end{array}$ & MRI Results \\
\hline $\begin{array}{l}1 \\
(\text { C9ORF72) }\end{array}$ & 200 & $\begin{array}{l}\text { Normal (Normal cerebellum, normal QSM, No parenchymal volume loss, No } \\
\text { signal abnormality) }\end{array}$ \\
\hline $\begin{array}{l}2 \\
(\text { C9ORF72) }\end{array}$ & 2 & $\begin{array}{l}\text { Unremarkable MRI of the brain for age. Subtle hyperintensity is noted along } \\
\text { the cortex of the precentral gyri bilaterally. Minimal increase iron deposition } \\
\text { in bilateral hand and face, normal cerebellum, minimal white matter } \\
\text { disease, no parenchymal volume loss, increased T2 signal in the } \\
\text { corticospinal tracts bilaterally. }\end{array}$ \\
\hline $\begin{array}{l}3 \\
(\text { C9ORF72) }\end{array}$ & 126 & $\begin{array}{l}\text { Asymmetric right more than left increased susceptibility within the motor } \\
\text { portion cortices with associated minimal diffusion hyperintensity involving } \\
\text { the right motor cortex and a subtle increased T2 signal within the } \\
\text { subcortical white matter of the bilateral precentral gyri. There is no } \\
\text { abnormal signal along the course of the cortical spinal tracts. These } \\
\text { findings have been reported in the setting of upper motor neuron diseases } \\
\text { such as PLS and ALS. Minimal nonspecific supratentorial white matter } \\
\text { disease most likely reflect chronic microvascular ischemia. Mild diffuse } \\
\text { parenchymal volume loss is also noted. Increased iron deposition in } \\
\text { bilateral hand and face, more on the right normal cerebellum, normal } \\
\text { temporal lobes. Corticospinal tracts look normal. }\end{array}$ \\
\hline 4 (C9ORF72) & & $\begin{array}{l}\text { No QSM, but SWI done showing bilateral, symmetric hand more than face } \\
\text { increased iron deposition. No parenchymal volume loss. Normal } \\
\text { cerebellum. Increased T2 signal in the corticospinal tracts. }\end{array}$ \\
\hline $\begin{array}{l}5 \\
\text { (C9ORF72) }\end{array}$ & 6 & $\begin{array}{l}\text { Motor cortex susceptibility WNL for age. Moderately increased iron } \\
\text { deposition in the face and hand. Subtle T2 increased signal in corticospinal } \\
\text { tracts. Normal cerebellum. Mild white matter disease. }\end{array}$ \\
\hline $\begin{array}{l}6 \\
(\text { C9ORF72) }\end{array}$ & 7 & $\begin{array}{l}\text { Questionable minimal increase in susceptibility effect within the posterior } \\
\text { cortex of the precentral gyri, most pronounced within the right facial } \\
\text { homunculus. Moderate global parenchymal volume loss with white matter } \\
\text { disease. Cerebellar volume loss is proportionate to other volume loss. } \\
\text { Mildly increased iron deposition in bilateral hand (symmetric) and face (on } \\
\text { the right more than left.) }\end{array}$ \\
\hline $\begin{array}{l}7 \\
(\text { C9ORF72) }\end{array}$ & & $\begin{array}{l}\text { Global atrophy. Normal cerebellum. Increased T2 signal in corticospinal } \\
\text { tracts. Increased iron deposition in hand and face more than leg. }\end{array}$ \\
\hline 8 (C9ORF72) & & $\begin{array}{l}\text { Apparent interval decrease in size of right-sided vestibular schwannoma. } \\
\text { Correlation with dedicated gadolinium enhanced posterior fossa imaging is } \\
\text { suggested for better characterization. Mild to moderate nonspecific } \\
\text { supratentorial white matter disease and a pattern most compatible with } \\
\text { chronic microvascular ischemia, stable since April 10, } 2017 \text { progressed } \\
\text { since November } 12,2012 \text {. No acute infarction. Mild abnormal asymmetric } \\
\text { increased and iron deposition within the posterior cortex of the precentral } \\
\text { gyri, left more than right, with involvement of the leg, hand and fascial } \\
\text { portion of the motor cortex homunculus. Vestibular schwannoma. Mild } \\
\text { increased iron deposition in the face more than hand. Moderate white } \\
\text { matter disease. Mild parenchymal volume loss. Normal cerebellum. Normal } \\
\text { corticospinal tracts. }\end{array}$ \\
\hline 9 & 200 & $\begin{array}{l}\text { Normal (Normal cerebellum, normal QSM, No parenchymal volume loss, No } \\
\text { signal abnormality) }\end{array}$ \\
\hline
\end{tabular}

Page 4/5 
Normal (Mild symmetrically qualitative increase in susceptibility effect within the bilateral motor cortices. No abnormal T2 hyperintensity is noted

(SOD1 along the expected course of the corticospinal tracts.)

A4V)

11

(SOD1

D90)
Bilateral QSM changes with corticospinal tract enhancement.

Magnetic resonance imaging of the brain demonstrates severe

supratentorial burden of disease manifest ed by prominent pericallosal and periventricular white matter disease foci, without diffusion restriction to suggest active demyelination. These findings most likely represent changes of demyelinating disorder such as multiple sclerosis.

\section{Declarations}

\section{The Hospital for Special Surgery IRB has approved this study.}

\section{Acknowledgements:}

Authors would like to acknowledge Dr. Dale Lange for his contributions to the C9ORF72 portion of this work. Since he stopped responding to inquiries regarding the work and manuscript, authors are unable to determine if he approves of this manuscript. Therefore, he is an acknowledgement instead of an author.

\section{References}

1. Gendron, TF et al. (2015). Cerebellar c9RAN proteins associate with clinical and neuropathological characteristics of C9ORF72 repeat expansion carriers. Acta Neuropathologica. 130(4) 559- 573.

2. Tan, RH et al. (2014). Cerebellar Integrity in the Amyotrophic Lateral Sclerosis - Frontotemporal Dementia Continuum. PLoS One, 9(8): e105632.

3. Pare et al. (2018). Misfolded SOD1 pathology in SALS. Nature scientific reports 18: 14223.

4. Schweitzer, A et al. (2015). Quantitative Susceptibility Mapping of the Motor Cortex in Amyotrophic Lateral Sclerosis and Primary Lateral Sclerosis. AJR Am J Roentgenol. 204(5): 1086-1092.

5. Acosta-Cabronero, Julio. (2018). Quantitative Susceptibility MRI to Detect Brain Iron in Amyotrophic Lateral Sclerosis. Radiology 289(1):180112.

6. Turner et al. (2005). Distinct cerebral lesions in sporadic and D90A SOD1 ALS. Brain 128(Pt 6):13239.

7. Kovacs, GG. (2015). Neuropathology of Neurodegenerative diseases: A practical guide. Page 218.

8. Cudkowicz et al. (1998). Limited corticospinal tract involvement in amyotrophic lateral sclerosis subjects with the A4V mutation in the copper/zinc superoxide dismutase gene. Annals of Neurology Jun;43(6):703-10. 